\title{
'|||||||||||||||||||||||||||||||||||||||||||||||||||||||||||||||||||||.
}

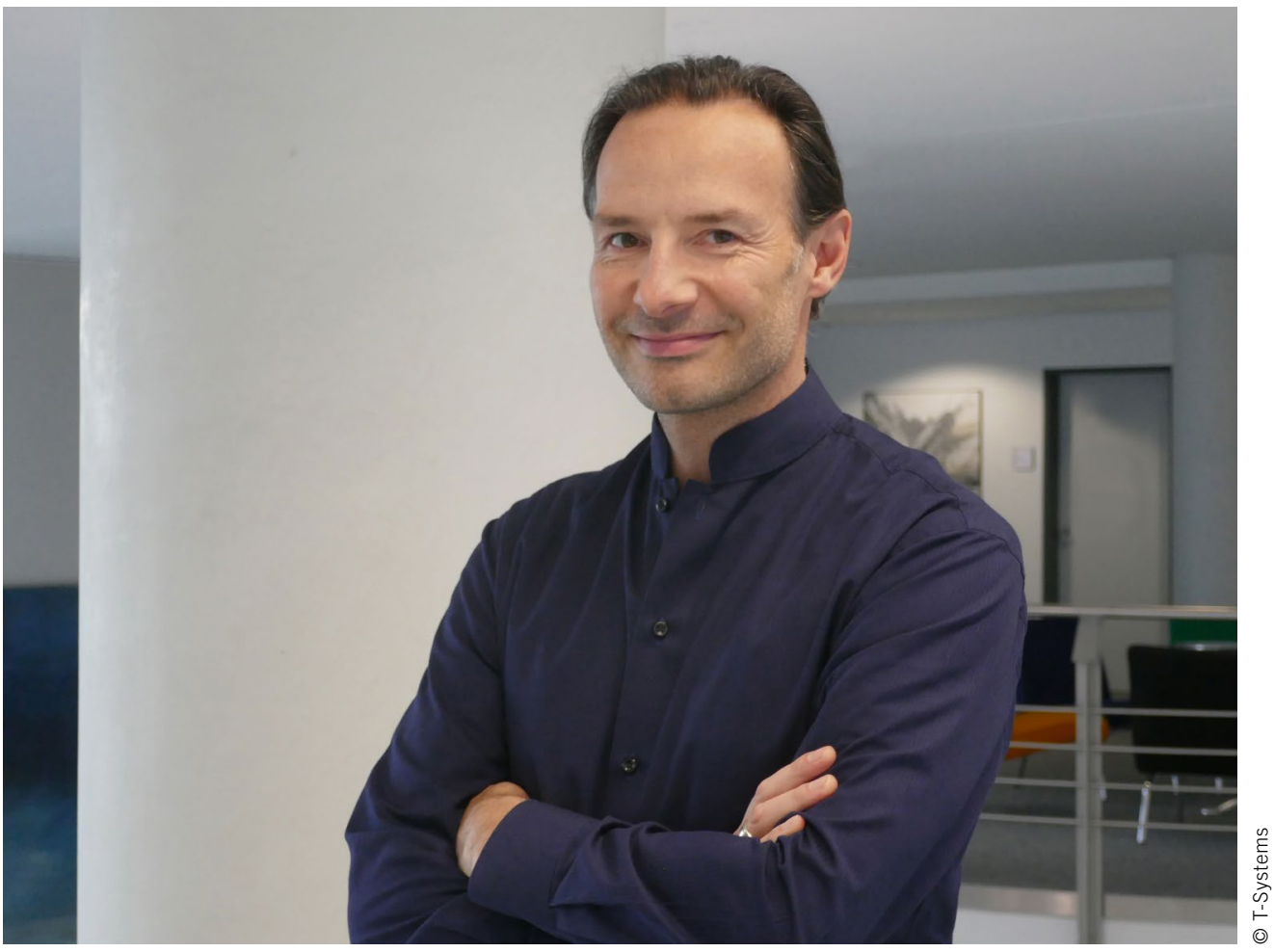

Joachim Klink

Head of Autonomous Driving and Integrated Mobility at

T-Systems International GmbH

\section{Teleoperation - When is it Going to Happen?}

Teleoperation, operating a vehicle or machine remotely, is not a new development, as examples from the construction industry, forestry or agriculture show. However, this technology is spurring a new fantasy for public road traffic in the context of autonomous driving, for example, when working on scenarios that, over a long distance of hundreds of kilometers, the driving function is executed completely from a distance. This could - according to the original idea - complement and safeguard autonomous driving functions: on the one hand as a fall-back level if the technology in the vehicle is overwhelmed with the driving task, and on the other hand as a design function when certain driving tasks are assigned to the vehicle itself and others to the teleoperator (example: automated snow removing vehicle for the airport apron, which is tele-driven to the area of operation and operates there automatically).

The extreme case, the operational remote driving of a passenger car in public transport, I consider fascinating for conferences and pilot projects, but not likely in real everyday life. Remote-controlled surveillance and combat drones, and not least our own evaluations, show that it is technically possible. In the end, it fails not because of the technology, but because of the economics. It is simply too expensive to develop the technology to the point where it would be possible to drive safely in public road traffic at any time and in any place.
So where and how will we see teleoperation in the near future? I see three directions where the economic benefits are favorable as a combination of safety, savings, and reasonable technical effort and cost: first, in the area of specialty vehicles and very specific operational scenarios, such as in mining, agriculture and forestry, or even in the port area. Here, humans can be kept out of the danger zone, and great savings or even the protection of life and limb of the driver justify the effort.

The second area deals with clearly delimitable private property with driving tasks such as logistics on factory premises or at airports, or with valet parking in multi-storey parking lots. Here, too, the operating conditions can be designed, and people can be protected. Positive business cases can be presented, although not quite as simply as in the first area.

The third area is dedicated to tactical and strategic teleoperation and the interaction between vehicle automation and teleoperator. Here, this operator does not take over the actual driving task but only the specification and monitoring of the functions "perception, planning, decision making" for an automated/autonomous vehicle.

In his hit "New York, New York," Frank Sinatra postulated: "If I can make it there, I'll make it anywhere." This is exactly true for teleoperation of passenger cars in public road traffic it is the ultimate in autonomous driving. 